\title{
MEASURING THE EFFECTS OF WORK MOTIVATION ON STRESS AND PERFORMANCE LINKAGES IN SME
}

\author{
Sheikh Muhamad Hizam Sheikh Khairuddin*, Zulkifli Saidun, \\ and Muhamad Shahrin Hashim
}

Universiti Kuala Lumpur Business School, Level 8, Bangunan Yayasan Selangor, No. 74, Jalan Raja Muda Abdul Aziz, Kg. Baru, 50300 Kuala Lumpur, Malaysia

*Corresponding author: sheikhmhizam@unikl.edu.my

Published online: 25 October 2019

To cite this article: Sheikh Khairuddin, S.M.H., Saidun, Z., and Hashim, M.S. (2019). Measuring the effects of work motivation on stress and performance linkages in SME. Asian Academy of Management Journal, 24(Supp. 2), 1-15. https://doi.org/10.21315/ aamj2019.24.s2.1

To link to this article: https://doi.org/10.21315/aamj2019.24.s2.1

\begin{abstract}
Entrepreneurship is important for the economic growth and wealth of the nation. Entrepreneurs are responsible for not only generating income to themselves but also to others in terms of job creation. However, the issue of the entrepreneurs' well-being is hardly being touched upon particularly in the context of stress, work motivation, and performance in enterprises of small and medium sizes in Malaysia. Work motivation as the mediator is the main contributions from the study. Therefore, the study aims to examine these relationships within this context. Stress, motivation, and performance were measured using A Shortened Stress Screening Tool (ASSET), Multidimensional Work Motivation Scale (MWMS), and Individual Work Performance (IWPQ), respectively. Questionnaires were distributed among the Majlis Amanah Rakyat (MARA) entrepreneurs located in Klang Valley and approximately 150 respondents responded. Data were analysed using the hierarchical multiple regression method. The results showed that certain stressors such as work relationship, work overload, job security, and resources and communication significantly affect motivation. Meanwhile, work motivation significantly predicts performance. Finally, stressors such as work relationships, work-life balance, job security, and pay and benefits significantly influence performance. Overall, work motivation partially mediated stress and performance relationship. Entrepreneurs should be aware of these significant stressors and conduct interventions so as to reduce their stresses and thus, improve their work motivation and performance.
\end{abstract}

Keywords: work motivation, stress, performance, entrepreneurs, ASSET, MWMS

(C) Asian Academy of Management and Penerbit Universiti Sains Malaysia, 2019. This work is licensed under the terms of the Creative Commons Attribution (CC BY) (http://creativecommons. org/licenses/by/4.0/). 


\section{INTRODUCTION}

The performance of small and medium-sized enterprises (SMEs) in Malaysia had improved recently. In particular, the gross domestic product (GDP) contribution of SME had increased steadily from 36.3\% in 2015 to $36.6 \%$ in 2016, which had been recorded at RM45.5 billion (Department of Statistics Malaysia, 2017). Also, the SME GDP grew at $5.2 \%$ which is quicker than the $4.2 \%$ of Malaysia GDP in 2016. Overall, SMEs clearly contributed to the nation's economy.

SMEs are categorised into micro, small, and medium businesses (SME Corp, 2017). Micro businesses are defined as businesses with sales turnover of less than RM300,000 and employ permanent employees of not more than 5 in manufacturing, services, and other sectors. Meanwhile, small businesses are those with turnover of sales between RM300,000 and RM15 million, and with employment of permanent employees from 5 to 75 in the manufacturing sector. However, in the services and other sectors, small businesses are defined as having RM300,000 to RM3 million of sales turnover with permanent employees from 5 to 30. Finally, medium businesses are defined as businesses with RM15 million to RM50 million in turnovers. These businesses employ permanent employees from 75 to 200 in the manufacturing sector. In the services and other sectors, businesses of medium size have turnover of sales between RM3 million to RM20 million and employ permanent employees from 30 to 75 . These categories of SMEs are not inclusive of companies which are public listed on the main board, corporations like multinational and government-linked, incorporated companies from the Ministry of Finance, enterprises owned by the state, and all of their subsidiaries. SMEs in this study came from entrepreneurs who took a business loan from Majlis Amanah Rakyat (MARA), a government agency under the Ministry of Rural and Regional Development, Malaysia. MARA's objective is to successfully develop innovative entrepreneurs, produce human capital with integrity and global mind set, contribute to ownership of equity, and make easier of delivery system (MARA, 2018). SMEs also face the risk of closing shop if not managed properly. In order to maintain and increase the performance of these SMEs, we also need to be sensitive and aware of the well-being of these entrepreneurs who operate and manage these businesses successfully. However, entrepreneurial stressors are hardly being found and studied upon (Grant \& Ferris, 2012). The identification of these stressors is important so as to determine the sources or causes of stress. Past research works on entrepreneurial stress are focused on role theories like role overload, role conflict, and role ambiguity (Buttner, 1992). Adopting the 
stress model from A Shortened Stress Screening Tool or ASSET (Cartwright \& Cooper, 2002), commonly found stressors at the workplace were used, i.e., work relationships, work-life balance, overload, job security, control, resources and communication, aspects of the job, and pay and benefits.

The effect of stress can be numerous. For example, stressors had been found to impair entrepreneurs' health (Buttner, 1992). Work motivation could suffer too (Wani, 2013). Entrepreneurial motivation is essential in providing and sustaining the drive, intensity, and persistence of the entrepreneur's behaviour in pursuing his career success and thus, business sustainability. In this study, motivation at work is measured through various components such as amotivation, external regulation, identified regulation, introjected regulation, and intrinsic motivation (Gagne et al., 2014).

As the extension to the effect of stress, poor work motivation due to stress will subsequently lead to poor individual work performance (Park et al., 2012). Individual work performance is important to entrepreneur in order to ensure efficiency and effectiveness as well as productivity in managing the business. Individual work performance is a key indicator to the team and organisational performance. Subsequently, this will contribute to the productivity and competitiveness of the company. Task performance, contextual performance, and counterproductive behaviour are dimensions measured in this study for individual work performance (Koopmans, 2014). Therefore, the study aims to: (1) examine the stressors' effect of work motivation; (2) determine the impact of stressors on individual work performance; (3) measure the effects of work motivation on individual work performance; and (4) determine the effects of mediation of work motivation on stress and performance of the entrepreneurs in Malaysian SMEs.

\section{LITERATURE REVIEW}

\section{Underpinning Theory}

The parent theory for this study is applied from Beehr and Newman's General Theory of Stress (1978). Within the domains of job stress, employee health, and organisational effectiveness, this theory consisted of seven elements or facets. They are personal, environmental, process, human consequences, organisational consequences, adaptive responses, and time facets. 


\section{Workplace Stressor}

Workplace stressors can be referred to as the stress sources that are found commonly at the workplace (Cartwright \& Cooper, 2002). The stress model, ASSET, consists of eight common workplace stressors, namely work relationships, work-life balance, overload, job security, control, resources and communication, aspects of the job, and pay and benefits. Working relationships between workers, bosses, subordinates, customers, etc., can be referred to as work relationships. The most stressful factor for Malaysian managers is work relationships (Manshor, Fontaine \& Choy, 2003). Entrepreneurs deal with all types of people in running their business. Therefore, any strained relationship could lead to stress. For work-life balance, work has the potential to spill over to lives and vice versa if not balanced (Cartwright \& Cooper, 2002). Women entrepreneurs will have a tough time in getting their work and life balance with their children in mind. Overload can be defined as a situation where the demand of the job becomes no longer manageable. Entrepreneurs can be overloaded with clients and operations of his/her company and in turn will feel stressful. Job security refers to life-time job security. Many companies today are facing financial crisis and have to retrench their employees. Furthermore, with the advent of new technologies, traditional jobs become obsolete. Entrepreneurs are also a vulnerable group in terms of job security. For example, a start-up faces a high risk of folding the company up if it fails to manage its cash flow carefully. Therefore, job security could be a potential source of stress. Control can be defined as the ability to control the environment and the work to be done. Entrepreneurs face with numerous constraints in terms of government rules and regulation that they are unable to make any decision. Therefore, the control factor could also be a potential source of stress for entrepreneurs. Any type of resources such as financial, infrastructure, technology, etc., that are communicated to stakeholders in the company can be referred to as resources and communication. An SME can be faced with limited resources and this might be stressful for the entrepreneurs in order for him/her to operate efficiently and effectively. Furthermore, poor communication between the stakeholders can also be a source of stress. The way people interact with other people in their job can be referred to as aspects of the job. An entrepreneur might be facing difficult clients in his/her job. Another example would be poor working conditions. An SME does not have the luxury of having a nice and huge office. Hence, a potential source of stress could be the aspects of the job. Lastly, pay and benefits are referred to as pay and benefits that the person received at the end of the day. In the beginning, an entrepreneur might not be paid at all and do not have any benefits due to the fact the company is running at a loss. This could put a constraint on his life and wellbeing and thus, increases his/her levels of stress. 


\section{Work Motivation}

According to self-determination theory, motivation is a multidimensional construct. The Multidimensional Work Motivation Scale (MWMS) consisted of amotivation, extrinsic regulation (material), extrinsic regulation (social), introjected regulation, identified regulation, and intrinsic motivation (Gagne et al., 2014). Amotivation can be defined as absence of motivation on an activity. An entrepreneur might face amotivation if the reward he/she received is not satisfying. Extrinsic regulation (material) refers to doing an activity that offers material gains such as money. An entrepreneur is motivated to build a career in business because he/she is driven by financial gains from the business. Extrinsic regulation (social) means doing an activity in order to please someone. An entrepreneur is motivated to apply a business license in order not to be punished by the authority. Introjected regulation refers to motivation of someone who feels he/she needs to be in control. An entrepreneur is motivated because he/she wants to prove to people that he/she can be successful. Identified regulation is volitional or a form of internalisation that one identifies a value and accept it as his own. An entrepreneur is motivated in his job because he/she feels that it is important to do so. Doing the activity for its own sake because it is enjoyable and interesting is referred to as intrinsic regulation. Freedom and autonomy in entrepreneurship could be a motivator for an entrepreneur to open a shop.

\section{Work Performance}

Campbell (1990) defined individual work performance as actions or behaviours pertaining to goals of the organisation. Meanwhile, Koopmans (2014) developed the Individual Work Performance Questionnaire using three constructs, namely task performance, contextual performance, and counterproductive work behaviour. The proficiency of individuals performing the core or technical tasks which are substantial and central to his/her job is referred to as task performance. For entrepreneurs, their task performance could be how well they source the company's finances, clients, and staff. Contextual performance is the behaviour that supports the function of technical core such as organisational, social, and psychological environment. Entrepreneurs are seen on their contextual performance by showing effort, supporting peer and team performance, communicating and cooperating. Counterproductive work behaviour is behaviour that is harming the well-being of the organisation. Entrepreneurs could indulge in counterproductive work behaviours such as absenteeism and theft. 


\section{Relationship Between Work Stressor, Motivation, and Performance}

There are three stress definitions and theories (Beehr \& Franz, 1987). Stimulusbased is the first. This theory stated that stress is the stimulus that can be found in the environment. The second definition of stress meanwhile, is responsebased. This second theory of stress posited that individuals will respond to stress psychologically and physiologically. Finally, the third stress theory asserted that stress is interactional-based. This is the most accepted theory of stress of stressorstrain relationships that combines both of the earlier theories. For empirical evidences, recent studies had revealed significant relationships between work stressor, motivation, and performance. Idris $(2010 ; 2011)$ discovered that role stressors like role overload, role conflict, and role ambiguity were significant in influencing strain. A study conducted by Wani (2013) revealed that stress of high levels led to low level motivation. Stress also had been discovered to affect work performance (Al-Khasawneh \& Futa, 2013; Veena \& Shailaja, 2016). Meanwhile, motivation was found to influence job performance (KuranchieMensah \& Amponsah-Tawiah, 2016). Finally, motivation was a mediator between work environmental factors and job performance linkages in a study conducted by Jayaweera (2015).

\section{Research Framework}

Figure 1 depicts the research framework of this study. This research framework comprises eight stressors, namely work relationships, work-life balance, overload, job security, control, resources and communication, aspects of the job, and pay and benefits as the independent variables. Meanwhile, a mediator, i.e., motivation is introduced in this framework. Finally, the dependent variable is individual work performance.

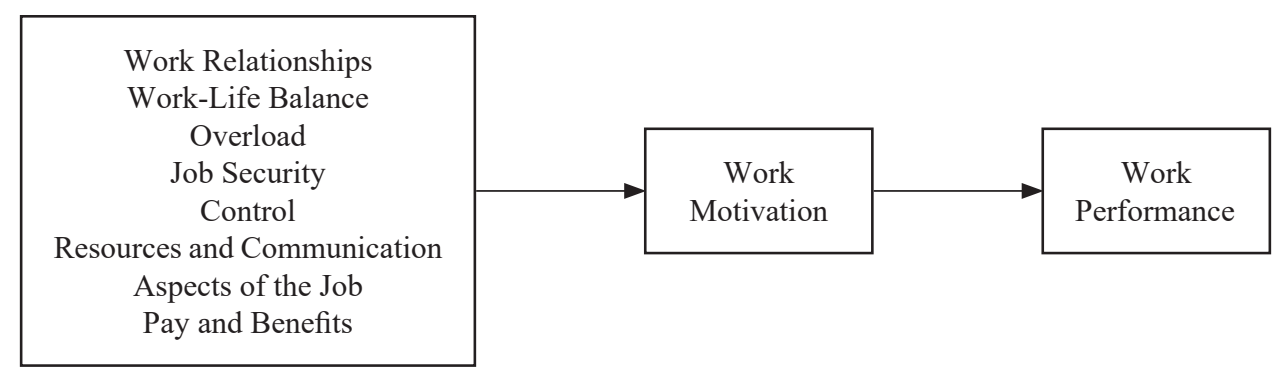

Figure 1. Research framework of stressors, motivation, and performance in SME 


\section{RESEARCH METHODOLOGY}

The design of this research is cross-sectional in nature. Data were taken only once compared to a longitudinal study. Respondents are MARA entrepreneurs from SMEs located in Klang Valley, Malaysia. A total population of 210 was identified. Therefore, 150 were selected based on the minimum sample size determined from the Krejcie and Morgan's table of minimum sample size (1970). The composition of the sample are entrepreneurs, managers, and executives from SMEs who took business loans from MARA. ASSET (Cartwright \& Cooper, 2002) was used to measure the levels of stress. For the sampling strategy, respondents were selected based on the list of MARA entrepreneurs through simple random sampling technique. A lottery method was chosen to undergo this process since the number of population is low. To made up the sample of the study, which is 150 entrepreneurs, each of the 210 entrepreneurs (which is the total population) was assigned a number between 1 to 210 , and out of the hat 150 numbers were chosen. Each entrepreneur, therefore, had an equal chance of being selected for the survey.

Work relationships, work-life balance, overload, job security, control, resources and communication, aspects of the job, and pay and benefits were measured from a 6-point scale ranging from 1 (Strongly Disagree) to 6 (Strongly Agree). Altogether, there are 37 items being measured for stressor. Meanwhile, MWMS (Gagne et al., 2014) was adopted to measure work motivation. Amotivation, extrinsic regulation (material), extrinsic regulation (social), introjected regulation, identified regulation, and intrinsic motivation are all measured using a 7-point scale ranging from 1 (Not at All) to 7 (Completely). A total of 19 items were measured for work motivation. Finally, work performance was measured using Koopmans' (2014) Individual Work Performance Questionnaire. Components of work performance such as task performance, contextual performance, and counterproductive work behaviour were measured using a 5-point rating scale ranging from 1 (Seldom) to 5 (Always). For individual work performance, the total number of items measured are 18. Overall, the total number of items for the survey are 74. Analysis of data include demographic characteristics, reliability, mean, standard deviation, correlation, multiple, simple, and hierarchical multiple regression, and mediation analysis. Demographic characteristics of the respondents analysed include gender, age, marital status, income, qualification, type of business, number of staff, and position. Items of stressor, work motivation, and individual work performance were also analysed in terms of their Cronbach's alpha for scale reliabilities. Multiple and simple regression analyses were used to analyse and make predictions between 
stressors and work motivation, stressors and individual work performance, and work motivation and individual work performance. Finally, mediation analysis was conducted using the 4-step approach with the last step utilising the hierarchical multiple regression technique.

\section{FINDINGS}

A response rate of $100 \%$ was achieved in this study; meaning that the whole 150 respondents selected earlier responded to the survey administered. From the data collected from the survey, demographic characteristics of these respondents were derived. They were analysed according to frequency (numbers) and percentages. In terms of gender, the number of female respondents surveyed are 93, while males are 57 . These accounted for $62 \%$ of females and $38 \%$ of males in the sample of respondents surveyed in this study. The age of the respondents varied accordingly: those below 21 years old recorded 8 people (5\%); age from 21 to 30 years old stood at 64 people (43\%; the highest); 31 to 40 years old stated 60 people (40\%); age from 41 to 50 years old accumulated 10 people (7\%); and finally, 51 to 60 years old gathered 8 people (5\%). For marital status, 93 respondents are married, which accounted for $62 \%$ of the total sample population. Meanwhile, those respondents who are still single are recorded at 57 , which comes to $38 \%$ of the total respondents surveyed. The income level of respondents can be divided into two categories: those earning less than RM5,000 per month; and those earning RM5,000 to RM10,000 per month. A number of 103 respondents fall into the first category which recorded approximately $69 \%$. Meanwhile, the second category of income level consisted of 47 respondents which accounted for $31 \%$ of the total respondents. In terms of academic qualification, respondents with secondary school education recorded the highest number at 79 people or $53 \%$. Those with diploma qualifications stood at 14 people or $9 \%$; bachelor's degree at 43 people or $29 \%$; and master's degree at 14 or $9 \%$. These respondents had different types of business or sectors. The highest are involved in the service sector which had 57 respondents or $38 \%$. The rest are as follows: manufacturing sector with 36 respondents (24\%); food sector with 29 respondents (19\%); telecommunication sector with 21 respondents $(14 \%)$; and finally, agriculture sector with 7 respondents $(5 \%)$. The number of staff in these businesses varied as well. Most of the respondents (114 or $76 \%$ ) had less than 10 staff. Meanwhile, 36 or $24 \%$ of the respondents had 11 to 50 staff employed in their business. Last but not least is the position of the respondents. Most of the respondents are Managing Directors (93 or 62\%). The rest are: Executives (29 or 19\%); Directors (14 or 9\%); General Managers (7 or 5\%); and Managers ( 7 or $5 \%)$. These results are summarised in Table 1. 
Table 1

Respondents' demographic characteristics

\begin{tabular}{|c|c|c|}
\hline Demographic characteristic & Frequency & Percentage $(\%)$ \\
\hline \multicolumn{3}{|l|}{ Gender } \\
\hline Male & 57 & 38 \\
\hline Female & 93 & 62 \\
\hline \multicolumn{3}{|l|}{ Age } \\
\hline Below 21 years & 8 & 5 \\
\hline $21-30$ years & 64 & 43 \\
\hline $31-40$ years & 60 & 40 \\
\hline $31-40$ years & 10 & 7 \\
\hline $41-50$ years & 8 & 5 \\
\hline $51-60$ years & & \\
\hline \multicolumn{3}{|l|}{ Marital } \\
\hline Married & 93 & 62 \\
\hline Single & 57 & 38 \\
\hline \multicolumn{3}{|l|}{ Income level } \\
\hline$<$ RM5,000 per month & 103 & 69 \\
\hline RM5,000 to 10,000 per month & 47 & 31 \\
\hline \multicolumn{3}{|l|}{ Academic qualification } \\
\hline Secondary school & 75 & 53 \\
\hline Diploma & 14 & 9 \\
\hline Degree & 43 & 29 \\
\hline Master & 14 & 9 \\
\hline \multicolumn{3}{|l|}{ Business/sector } \\
\hline Service & 57 & 38 \\
\hline Manufacturing & 36 & 24 \\
\hline Food & 29 & 19 \\
\hline Food & 21 & 14 \\
\hline Telecommunication & 7 & 5 \\
\hline Agriculture & & \\
\hline \multicolumn{3}{|l|}{ Number of employees } \\
\hline$<10$ staff & 114 & 76 \\
\hline $11-50 \mathrm{staff}$ & 36 & 24 \\
\hline \multicolumn{3}{|l|}{ Position } \\
\hline Managing Director & 93 & 62 \\
\hline Executive & 29 & 19 \\
\hline Director & 14 & 9 \\
\hline General Manager & 7 & 5 \\
\hline $\begin{array}{l}\text { General Manager } \\
\text { Manager }\end{array}$ & 7 & 5 \\
\hline
\end{tabular}


Cronbach's alpha was used to measure reliability of the scales of the instrument of this study. The results showed that work relationship is at the Cronbach's alpha value of 0.78 (Acceptable); work-life balance at 0.77 (Acceptable); overload at 0.75 (Acceptable); job security at 0.80 (Good); control at 0.81 (Good); resources and communication at 0.79 (Acceptable); aspects of the job at 0.83 (Good); work motivation at 0.84 (Good); and work performance at 0.86 (Good). From the reliability analysis conducted above, we can say that all the scales that had been used for this study are good and acceptable.

Table 2 depicts the results of multiple regression analysis of work motivation on work stressor. Significant stressors such as work relationships $(\beta=-0.223$, $p=0.006)$, overload $(\beta=-0.152, p=0.020)$, job security $(\beta=-0.236, p=0.000)$, and resources and communication $(\beta=-0.180, p=0.008)$ predicted negative work motivation. R-squared $\left(\mathrm{R}^{2}\right)$ of the model showed that $33.3 \%$ of the variances in predicting work motivation was explained.

Table 2

Multiple regression of work motivation on work stressor

\begin{tabular}{|c|c|c|c|c|c|c|}
\hline & & \multicolumn{2}{|c|}{$\begin{array}{l}\text { Unstandardised } \\
\text { coefficients }\end{array}$} & \multirow{2}{*}{$\begin{array}{c}\begin{array}{c}\text { Standardised } \\
\text { coefficients }\end{array} \\
\beta\end{array}$} & \multirow[t]{2}{*}{$\mathrm{t}$} & \multirow[t]{2}{*}{ Sig. } \\
\hline & & B & Std. error & & & \\
\hline \multirow[t]{12}{*}{1} & (Constant) & 7.077 & 0.282 & & 25.055 & 0.000 \\
\hline & Work relationships & -0.243 & 0.131 & -0.223 & -1.854 & 0.006 \\
\hline & Work-life balance & -0.027 & 084 & -0.032 & -0.315 & 0.753 \\
\hline & Overload & -0.140 & 0.082 & $-0.152^{*}$ & -1.705 & 0.020 \\
\hline & Job security & -0.151 & 105 & -0.236 & -1.438 & 0.000 \\
\hline & Control & -0.041 & 114 & -0.043 & -0.361 & 0.719 \\
\hline & Resources and comm. & -0.116 & 0.107 & -0.180 & -1.084 & 0.008 \\
\hline & Aspects of the job & -0.066 & 0.111 & -0.057 & -0.591 & 0.555 \\
\hline & Pay and benefits & -0.018 & 0.067 & -0.026 & -0.274 & 0.784 \\
\hline & $\mathrm{R}$ & 0.577 & & & & \\
\hline & $\mathrm{R}^{2}$ & 0.333 & & & & \\
\hline & $\mathrm{F}$ & $8.789^{* *}$ & & & & \\
\hline
\end{tabular}

**0.01 level; * 0.05 level

For the relationship between work motivation and work performance, a simple regression analysis technique was conducted. In this test, work motivation was positive and significant in predicting work performance $(\beta=0.624 ; p=0.000)$. The $\mathrm{R}^{2}$ of this model was 0.789 , meaning that $78.9 \%$ of the variance predicting work performance was explained by this model. Table 3 show these results. 
Table 3

Simple regression analysis of work performance on work motivation

\begin{tabular}{|c|c|c|c|c|c|c|}
\hline & & \multicolumn{2}{|c|}{$\begin{array}{l}\text { Unstandardised } \\
\text { coefficients }\end{array}$} & \multirow{2}{*}{$\begin{array}{c}\text { Standardised } \\
\text { coefficients }\end{array}$} & \multirow[t]{2}{*}{$\mathrm{t}$} & \multirow{2}{*}{ Sig. } \\
\hline & & B & Std. error & & & \\
\hline \multirow[t]{5}{*}{1} & (Constant) & 0.412 & 0.161 & & 2.564 & 0.011 \\
\hline & Work motivation & 0.900 & 0.031 & 0.624 & 29.478 & 0.000 \\
\hline & $\mathrm{R}$ & 0.624 & & & & \\
\hline & $\mathrm{R}^{2}$ & 0.789 & & & & \\
\hline & $\mathrm{F}$ & $868.971^{* *}$ & & & & \\
\hline
\end{tabular}

Multiple regression analysis technique was conducted in order to predict work performance on the stressors. Similarly, certain stressors were found to predict work performance. Work relationships $(\beta=-0.165 ; \mathrm{p}=0.003)$, work-life balance $(\beta=-0.188 ; p=0.001)$, job security $(\beta=-0.193 ; p=0.000)$ and pay and benefits $(\beta=-0.196 ; p=0.000)$ were negative and significantly predicted work performance. $\mathrm{R}^{2}$ for this model was 0.345 , indicating that $34.5 \%$ of the variance in predicting work performance was explained by the model. In contrast, overload, control, and aspects of the job were all not significant.

To test work motivation as the mediator between stressors and work performance, the four-step approach of mediation analysis procedures of Baron and Kenny (1986) were applied. In the first step, all the independent variables, IV (stressors) were correlated with the dependent variable, DV (work performance). Next, in second step, all the IVs were significantly correlated with the mediating variable, MV (work motivator). In the third step, the MV was correlated significantly with the DV. To run the fourth step, a hierarchical multiple regression analysis (HMRA) technique was employed. In this final step, both the IVs and MV must predict DV. If IV is still significant when MV is entered to the model, then partial mediation existed. However, if IV is no longer significant when the MV is entered, then full mediation occurred. In this test, work motivation was a partial mediator. Stressors were entered into the model predicting work relationship and yielded the $\mathrm{R}^{2}$ of 0.345 or $34.5 \%$ in the first step. In the second step, work motivation was entered and the $\mathrm{R}^{2}$ changes to 0.465 or $46.5 \%$. This can be interpreted in the $\mathrm{R}^{2}$ change as a 0.120 or $12 \%$ contribution of work motivation to the model predicting work performance $\left(\Delta \mathrm{R}^{2}=0.120 ; \Delta \mathrm{F}\right.$ statistics $\left.=18.817 ; \mathrm{p}<0.01\right)$. Stressors that remained significant but had been reduced were work relationship $(\beta=-0.155$; $\mathrm{p}<0.05)$, work-life balance $(\beta=-0.137 ; \mathrm{p}<0.05)$, overload $(\beta=-0.118 ; \mathrm{p}<0.05)$, and pay and benefits $(\beta=-0.180 ; p<0.05)$. Work motivation was also significant 
in predicting work performance $(\beta=0.383 ; \mathrm{p}<0.01)$. This is a partial mediation effect. Other stressors such as job security, control, resources and communication, and pay and benefit however were not significant.

Table 4

HMRA of performance on stressor and motivation

\begin{tabular}{|c|c|c|c|c|c|c|}
\hline \multirow{2}{*}{ Variable } & \multicolumn{3}{|c|}{ Step 1} & \multicolumn{3}{|c|}{ Step 2} \\
\hline & B & SE & $\beta$ & $\mathrm{B}$ & SE & $\beta$ \\
\hline Work relationships & -0.207 & 0.126 & $-0.165^{*}$ & -0.006 & 0.106 & $-0.155^{*}$ \\
\hline Work-life balance & -0.006 & 0.081 & $-0.188^{*}$ & -0.017 & 0.068 & $-0.137^{*}$ \\
\hline Overload & -0.150 & 0.079 & -0.167 & -0.074 & 0.067 & $-0.118^{*}$ \\
\hline Job security & -0.090 & 0.101 & $-0.193^{* *}$ & -0.039 & 0.085 & -0.052 \\
\hline Control & -0.023 & 0.110 & -0.024 & -0.010 & 0.092 & -0.015 \\
\hline Resources and comm. & -0.212 & 0.103 & -0.227 & -0.144 & 0.086 & -0.176 \\
\hline Aspects of the job & -0.093 & 0.107 & -0.083 & -0.121 & 0.092 & -0.151 \\
\hline Pay and benefits & -0.025 & 0.064 & $-0.196^{* *}$ & -0.099 & 0.054 & $-0.180^{*}$ \\
\hline Work motivation & & & & 0.359 & 0.037 & 0.383 \\
\hline $\mathrm{R}^{2}$ & & 0.345 & & & 0.465 & \\
\hline$\Delta \mathrm{R}^{2}$ & & & & & 0.120 & \\
\hline$\Delta \mathrm{F}$ statistics & & $9.282^{* *}$ & & & $18.817^{* *}$ & \\
\hline
\end{tabular}

** 0.01 level; $* 0.05$ level

These findings are summarised in Table 5.

Table 5

Summary of findings

\begin{tabular}{ll}
\hline Relationship & Results \\
\hline Stressors and work motivation & Stressors significantly predicted work motivation. \\
Work motivation and work performance & $\begin{array}{l}\text { Work motivation significantly predicted work } \\
\text { performance. }\end{array}$ \\
Stressors and work performance & Stressors significantly predicted work performance. \\
Stressors, work motivation, and work & Work motivation was significant in predicting \\
performance & work performance. Stressors had been reduced \\
& but remained significant (partial mediation). \\
\hline
\end{tabular}




\section{DISCUSSION AND CONCLUSION}

The findings from the study revealed that certain stressors influenced work performance of the entrepreneurs. Despite having high motivation for success, entrepreneurs are not invincible in terms of stress as this study had shown. This study not only contributes in extending the theories of stress by including work motivation as the mediator of this relationship but also practice. In terms of practice, the findings indicated interventions of stress at the workplace by the entrepreneurs and MARA. The entrepreneurs and MARA must be aware and take action regarding significant stressors found in SMEs. Motivation will deteriorate unless interventions are in place to reduce or eliminate significant stressors found in this study such as work relationship, overload, job security, and resources and communication. Work relationships can be enhanced through training. Spirit of cooperation will be derived in an adventure-like setting of training, for example. Key performance indicators of performance of balanced workload can be improved through negotiations between subordinate and superior. Job security policy in SME can be better by providing pension plan for the employees. Although resources are scarce in SMEs, an effective communication plan can enhance the understanding of the situation at the workplace and improve the employees' motivation. Meanwhile, work performance will be affected by certain stressors like work relationships, work-life balance, job security, and pay and benefits. Indeed, work motivation is significant in affecting work performance of the entrepreneurs. In terms of work performance, work-life balance can be improved for example, by having flexible hour policy in SME. Meanwhile, pay and benefits can also be enhanced as to be competitive in the labour market so as to improve the employees' performance. In this study, work motivation was found to be a partial mediator between stressors and performance linkages. This means that as a result of stress, entrepreneurs not only suffer from poor work motivation but also deteriorating work performance. Therefore, it is imperative for entrepreneurs in SME in particular to intervene these stress process. The findings also suggested that MARA can take the initiative to assist their entrepreneurs in coping with stress by giving them a proper stress management training. In this way, the entrepreneurs are able to anticipate what is coming in term of stressors and their consequences. Similarly, individual entrepreneurs are also encouraged to attend these types of training themselves in order to be familiar with the stress process. As for the limitations, the study employed a cross-sectional survey. Therefore, for future research, a longitudinal methodology is recommended for further verification of the causal factors. 


\section{REFERENCES}

Al-Khasawneh, A.L., \& Futa, S.M. (2013). The relationship between job stress and nurses performance in the jordanian hospitals: A case study in King Abdullah the Founder Hospital. Asian Journal of Business Management, 5(2), 267-275. https://doi.org/10.19026/ajbm.5.5701

Baron, R.M., \& Kenny, D.A. (1986). The moderator-mediator variable distinction in social psychological research: Conceptual, strategic, and statistical considerations. Journal of Personality and Social Psychology, 51(6), 1173-1182. https://doi. org/10.1037//0022-3514.51.6.1173

Beehr, T.A., \& Franz, T.M. (1987). The current debate about the meaning of job stress. In J.M. Ivancevich, \& D.C. Ganster (Eds.), Job stress: From theory to suggestion (pp. 5-18). New York: Haworth Press. https://doi.org/10.1300/J075v08n02_02

Buttner, E.H. (1992). Entrepreneurial stress: Is it hazardous to your health? Journal of Managerial Issues, 4(2), 223-240.

Beehr, T.A., \& Newman, J.E. (1978). Job stress, employee health and organizational effectiveness: A facet analysis, model, and literature review. Personnel Psychology, 31, 665-699. https://doi.org/10.1111/j.1744-6570.1978.tb02118.x

Campbell, J.P. (1990). Modeling the performance prediction problem in industrial and organizational psychology. In M.D. Dunnette, \& L.M. Hough (Eds.), Handbook of industrial and organizational psychology (pp. 687-732). Palo Alto, CA: Consulting Psychologists Press.

Cartwright, S., \& Cooper, C.L. (2002). ASSET: The management guide. Manchester: Robertson Cooper.

Department of Statistics Malaysia. (2017). Press release: Small and medium enterprises gross domestic products (SMEs GDP) 2016. Retrieved 18 February 2018 from https://www.dosm.gov.my/v1/index.php?r=column/ pdfPrev\&id=YzI2NWE2U0tXS1VEdnFsWHpqM1Fudz09.

Gagne, M., Forest, J., Vansteenkiste, M., Crevier-Braud, L., Van den Broeck, A., Aspeli, A.K., Bellerose, J., Benabou, C., Chemolli, E., Güntert, S.T., Halvari, H., Indiyastuti, D.L., Johnson, P.A., Molstad, M.H., Naudin, M., Ndao, A., Olafsen, A.H., Roussel, P., Wang, Z., \& Westbye, C. (2014). The Multidimensional Work Motivation Scale: Validation evidence in seven languages and nine countries. European Journal of Work and Organizational Psychology, 24(2), 178-196. https://doi.org/10.1080/1359432X.2013.877892

Grant, S., \& Ferris, K. (2012). Identifying sources of occupational stress in entrepreneurs for measurement. International Journal of Entrepreneurial Venturing, 4(4), 1-23. https://doi.org/10.1504/IJEV.2012.049828

Idris, M.K. (2010). Strain in teaching and research: Structural equation modeling approach. International Journal of Economics and Management, 4(1), 137-154.

Idris, M.K. (2011). Longitudinal effects of role stressors on strain: A comparison between three competing analytical approaches. International Journal of Economics and Management, 5(1), 98-113. 
Jayaweera, T. (2015). Impact of work environmental factors on job performance, mediating role of work motivation: A study of hotel sector in England. International Journal of Business and Management, 10(3), 271-278. https://doi.org/10.5539/ijbm. v10n3p271

Koopmans, L. (2014). Measuring individual work performance. Retrieved 18 February 2018 from https://publications.tno.nl/publication/34609635/BTWAre/koopmans2014-measuring.pdf.

Krejcie, R.V., \& Morgan, D.W. (1970). Determining sample size for research activities. Educational and Psychological Measurement, 30, 607-610.

Kuranchie-Mensah, E.B., \& Amponsah-Tawiah, K. (2016). Employee motivation and work performance: A comparative study of mining companies in Ghana. Journal of Industrial Engineering and Management, 9(2), 255-309. https://doi. org/10.3926/jiem. 1530

Manshor, A.T., Fontaine, R., \& Choy, C.S. (2003). Occupational stress among managers: A Malaysian survey. Journal of Managerial Psychology, 18(6), 622-628. https://doi.org/10.1108/02683940310494412

MARA. (2018). Majlis Amanah Rakyat official website. Retrieved 18 February 2018 from http://www.mara.gov.my/.

Park, J., Chung, S., An, H., Park, S., Lee, C., Kim, S.Y., Lee, J-D., \& Kim, K-S. (2012). A structural model of stress, motivation, and academic performance in medical students. Psychiatry Investigation, 9, 143-149. https://doi.org/10.4306/ pi.2012.9.2.143

SME Corp. (2017). SME Corp Malaysia official website. Retrieved 18 February 2018 from http:/www.smecorp.gov.my/index.php/en/policies/2015-12-21-09-09-49/ sme-definition.

Veena, N., \& Shailaja, S. (2016). Stress and academic performance. The International Journal of Indian Psychology, 3(3), 71-82.

Wani, S.K. (2013). Job stress and its impact on employee motivation: A study of a select commercial bank. International Journal of Business and Management Invention, 2(3), 13-18. 